Development of a Database-Driven System for Simulating Water Temperature in the Lower Yakima River Main Stem, Washington, for Various Climate Scenarios

Open-File Report 2013-1010 



\section{Development of a Database-Driven System for Simulating Water Temperature in the Lower Yakima River Main Stem, Washington, for Various Climate Scenarios}

By Frank Voss and Alec Maule

Open-File Report 2013-1010

U.S. Department of the Interior

U.S. Geological Survey 


\section{U.S. Department of the Interior \\ KEN SALAZAR, Secretary}

\section{U.S. Geological Survey \\ Marcia K. McNutt, Director}

U.S. Geological Survey, Reston, Virginia: 2013

For more information on the USGS-the Federal source for science about the Earth, its natural and living resources, natural hazards, and the environment-visit http://www.usgs.gov or call 1-888-ASK-USGS

For an overview of USGS information products, including maps, imagery, and publications, visit $h$ ttp://www.usgs.gov/pubprod

To order this and other USGS information products, visit http://store.usgs.gov

Suggested citation:

Voss, Frank, and Maule, Alec, 2013, Development of a database-driven system for simulating water temperature in the lower Yakima River main stem, Washington, for various climate scenarios: U.S. Geological Survey Open-File Report 2013-1010, 20 p.

Any use of trade, product, or firm names is for descriptive purposes only and does not imply endorsement by the U.S. Government.

Although this report is in the public domain, permission must be secured from the individual copyright owners to reproduce any copyrighted material contained within this report. 


\section{Contents}

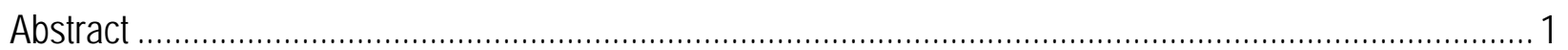

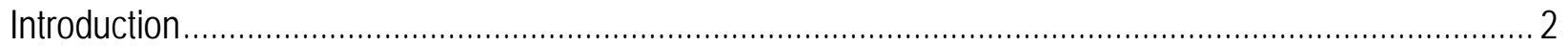

Methods

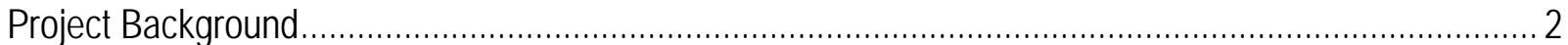

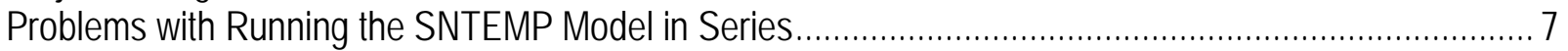

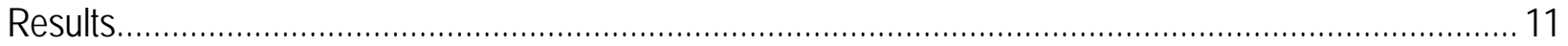

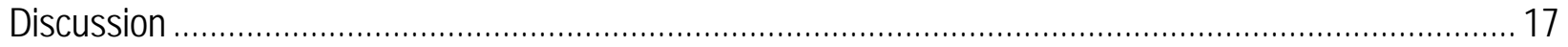

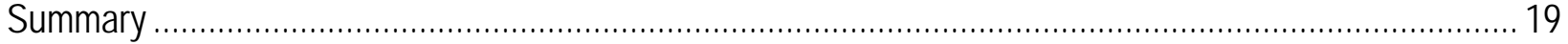

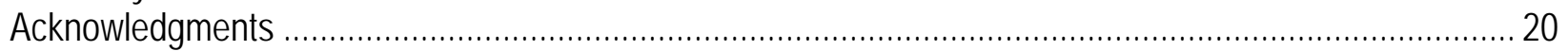

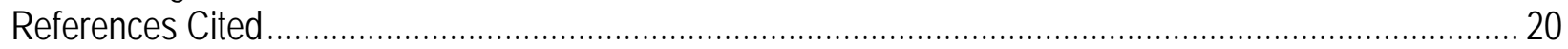

\section{Figures}

Figure 1. Map showing extent of modeled reach of the lower Yakima River main stem, Washington, with model endpoints and model output locations. ......................................................................... 3

Figure 2. Schematic diagram showing model for the Yakima River main stem with all modeled inflows and outflow for all seven model sections between Roza Dam and West Richland, Washington. ...... 4 Figure 3. Graph showing monthly air temperature increases applied to the Current Conditions scenario to create the adjusted air temperatures for the Plus 2 and Plus 1 climate scenarios. ..................... 5

Figure 4. Diagram showing logic flow for Model Automation Program.................................................. 10

Figure 5. Graph, created with first graphing tool, showing difference in mean monthly water temperature between the Plus 1 and Current Conditions scenarios for all output locations on the modeled Yakima River main stem, Washington, May, June, and July... 12

Figure 6. Graph, created with first graphing tool, showing difference in mean monthly water temperature between the Plus 1 and Current Conditions scenarios for all output locations on the modeled Yakima River main stem, Washington, August, September, and October.

Figure 7. Graph, created with second graphing tool, showing difference in mean monthly water temperature between the Plus 1 and the Current Conditions climate scenarios for selected output locations on the modeled Yakima River main stem, Washington.

Figure 8. Graph, created with third graphing tool, showing difference in simulated mean daily water temperature between Plus 1 and Plus 2 scenarios and the Current Conditions scenario for the site at a distance of 194.47 kilometers upstream of the mouth of the Yakima River, Washington 14

Figure 9. Graph, created with third graphing tool, showing difference in simulated mean daily water temperature between Plus 1 and Plus 2 scenarios and Current Conditions scenario for the site at a distance of 184.25 kilometers upstream of the mouth of the Yakima River, Washington. 15 Figure 10. Graph, created with third graphing tool, showing difference in simulated mean daily water temperature between Plus 1 and Plus 2 scenarios and Current Conditions scenario for the site at a distance of 168.42 kilometers upstream of the mouth of the Yakima River, Washington. 15 Figure 11. Graph, created with third graphing tool, showing difference in simulated mean daily water temperature between Plus 1 and Plus 2 scenarios and Current Conditions scenario for the site at a distance of 88.57 kilometers upstream of the mouth of the Yakima River, Washington. 16 Figure 12. Graph, created with third graphing tool, showing difference in simulated mean daily water temperature between Plus 1 and Plus 2 scenarios and Current Conditions scenario for the site at a distance of 50 kilometers upstream of the mouth of the Yakima River, Washington. 


\section{Tables}

Table 1. Typical input files for one Stream Network Temperature Model ............................................... 6

Table 2. Stream Network Temperature Model input files that had to be swapped in and out of the processing directory for each of the 25 years in a simulation period

Table 3. Stream Network Temperature Model input files that had to be swapped in and out of the processing directory for each of the seven segments.

Table 4. Average daily mean water temperature for Kiona, Washington 2002-05.

\section{Conversion Factors and Datums}

\section{Conversion Factors}

\begin{tabular}{lll}
\hline & \multicolumn{1}{c}{ Bultiply } & \multicolumn{1}{c}{ To obtain } \\
\hline & Length & \\
\hline mile (mi) & 1.609 & kilometer $(\mathrm{km})$ \\
kilometer $(\mathrm{km})$ & 0.6214 & mile (mi) \\
\hline
\end{tabular}

Temperature in degrees Celsius $\left({ }^{\circ} \mathrm{C}\right)$ may be converted to degrees Fahrenheit $\left({ }^{\circ} \mathrm{F}\right)$ as follows:

${ }^{\circ} \mathrm{F}=\left(1.8 \times{ }^{\circ} \mathrm{C}\right)+32$

\section{Datums}

Vertical coordinate information is referenced to the North American Vertical Datum of 1988 (NAVD 88). Horizontal coordinate information is referenced to the North American Datum of 1983 (NAD 83).

Altitude, as used in this report, refers to distance above the vertical datum. 


\title{
Development of a Database-Driven System for Simulating Water Temperature in the Lower Yakima River Main Stem, Washington, for Various Climate Scenarios
}

\author{
By Frank Voss and Alec Maule
}

\section{Abstract}

A model for simulating daily maximum and mean water temperatures was developed by linking two existing models: one developed by the U.S. Geological Survey and one developed by the Bureau of Reclamation. The study area included the lower Yakima River main stem between the Roza Dam and West Richland, Washington. To automate execution of the labor-intensive models, a database-driven model automation program was developed to decrease operation costs, to reduce user error, and to provide the capability to perform simulations quickly for multiple management and climate change scenarios. Microsoft ${ }^{\odot}$ SQL Server 2008 R2 Integration Services packages were developed to (1) integrate climate, flow, and stream geometry data from diverse sources (such as weather stations, a hydrologic model, and field measurements) into a single relational database; (2) programmatically generate heavily formatted model input files; (3) iteratively run water temperature simulations; (4) process simulation results for export to other models; and (5) create a database-driven infrastructure that facilitated experimentation with a variety of scenarios, node permutations, weather data, and hydrologic conditions while minimizing costs of running the model with various model configurations.

As a proof-of-concept exercise, water temperatures were simulated for a "Current Conditions" scenario, where local weather data from 1980 through 2005 were used as input, and for "Plus 1" and "Plus 2" climate warming scenarios, where the average annual air temperatures used in the Current Conditions scenario were increased by 1 degree Celsius $\left({ }^{\circ} \mathrm{C}\right)$ and by $2{ }^{\circ} \mathrm{C}$, respectively.

Average monthly mean daily water temperatures simulated for the Current Conditions scenario were compared to measured values at the Bureau of Reclamation Hydromet gage at Kiona, Washington, for 2002-05. Differences ranged between $1.9^{\circ}$ and $1.1^{\circ} \mathrm{C}$ for February, March, May, and June, and were less than $0.8^{\circ} \mathrm{C}$ for the remaining months of the year. The difference between current conditions and measured monthly values for the two warmest months (July and August) were $0.5^{\circ} \mathrm{C}$ and $0.2^{\circ} \mathrm{C}$, respectively. The model predicted that water temperature generally becomes less sensitive to air temperature increases as the distance from the mouth of the river decreases. As a consequence, the difference between climate warming scenarios also decreased. The pattern of decreasing sensitivity is most pronounced from August to October. 
Interactive graphing tools were developed to explore the relative sensitivity of average monthly and mean daily water temperature to increases in air temperature for model output locations along the lower Yakima River main stem.

\section{Introduction}

A methodology for linking and operating models using readily available and inexpensive software is described in this report. The methodology was applied to link water temperature models in series and to perform multiple simulations to predict daily maximum and mean water temperatures in the lower reach of the Yakima River basin for three climate scenarios. The predicted water temperatures from the model were used as input to other models in a decision support system developed for potentially managing resources in the Yakima River basin. The study area is located in the lower valley of the Yakima River basin in south-central Washington. The lower valley is in the rain shadow of the Cascade Mountains and only receives $10 \mathrm{~cm}$ of annual precipitation which mostly occurs between late autumn and early spring. As a result, the agricultural land in the valley is irrigated with water that is stored in a series of reservoirs in the upper basin. For a more detailed description of the study area see Voss and others (2008).

\section{Methods}

\section{Project Background}

Two existing water temperature models were linked for the project: (1) a U.S. Geological Survey (USGS) model extending on the Yakima River main stem from the Roza Diversion Dam to the Prosser Dam, and (2) a Bureau of Reclamation (Reclamation) model extending from the Prosser Dam to the 224 bridge at West Richland, Washington (fig. 1). The development of the USGS model is documented by Voss and others (2008), and the development of the Bureau of Reclamation model is by Payne, Bremm, and Monk (2001). The Stream Network Temperature Model (SNTEMP) was used in both studies to simulate water temperatures.

SNTEMP is a mechanistic heat transport model that predicts water temperature as a function of stream distance and environmental heat flux. SNTEMP has been used successfully in documented water temperature studies and has many useful features. For example, the model executable file is free to download, it has a fast run-time, and it uses readily available input data (such as local weather data for climate inputs and topographic maps and field measurements for stream geometry). SNTEMP also can simulate stream networks of any size or order and can use simulation time steps ranging from 1 day to 1 month. The model's documentation states that SNTEMP is capable of simulating water temperatures to within $0.5 \mathrm{C}^{\circ}$ of measured mean temperatures, given representational data for a user-selected time step. SNTEMP also is supported with a web site that provides a downloadable user's manual, a free online water-temperature modeling course, a bibliography of SNTEMP study reports, a Frequently Asked Questions section, and a publication on how to conduct water temperature modeling studies (Bartholow, 2000). SNTEMP software and documentation can be downloaded from a USGS Fort Collins Science Center web site (USGS, 2012).

The heat transport model in SNTEMP is based on the dynamic temperature-steady flow equation that assumes that all input data for meteorological and hydrological variables are average values for the simulation time step used. To obtain a daily time step, the length of a model had to equal the distance that a volume of water would travel in a single day (that is, travel time) under steady-flow conditions. Because high water temperature usually is of most concern during periods 
of low flow and high air temperatures, the USGS and Reclamation models were developed to simulate water temperatures during the growing season, when temperatures are warmest and flows are regulated for crop irrigation. Travel time for the study reach was estimated to be 7 days based on field measurements made by the USGS (Voss and others, 2008). Therefore, to model the entire main stem, seven reach models needed to be linked in series to produce the required daily values for maximum and mean water temperatures.

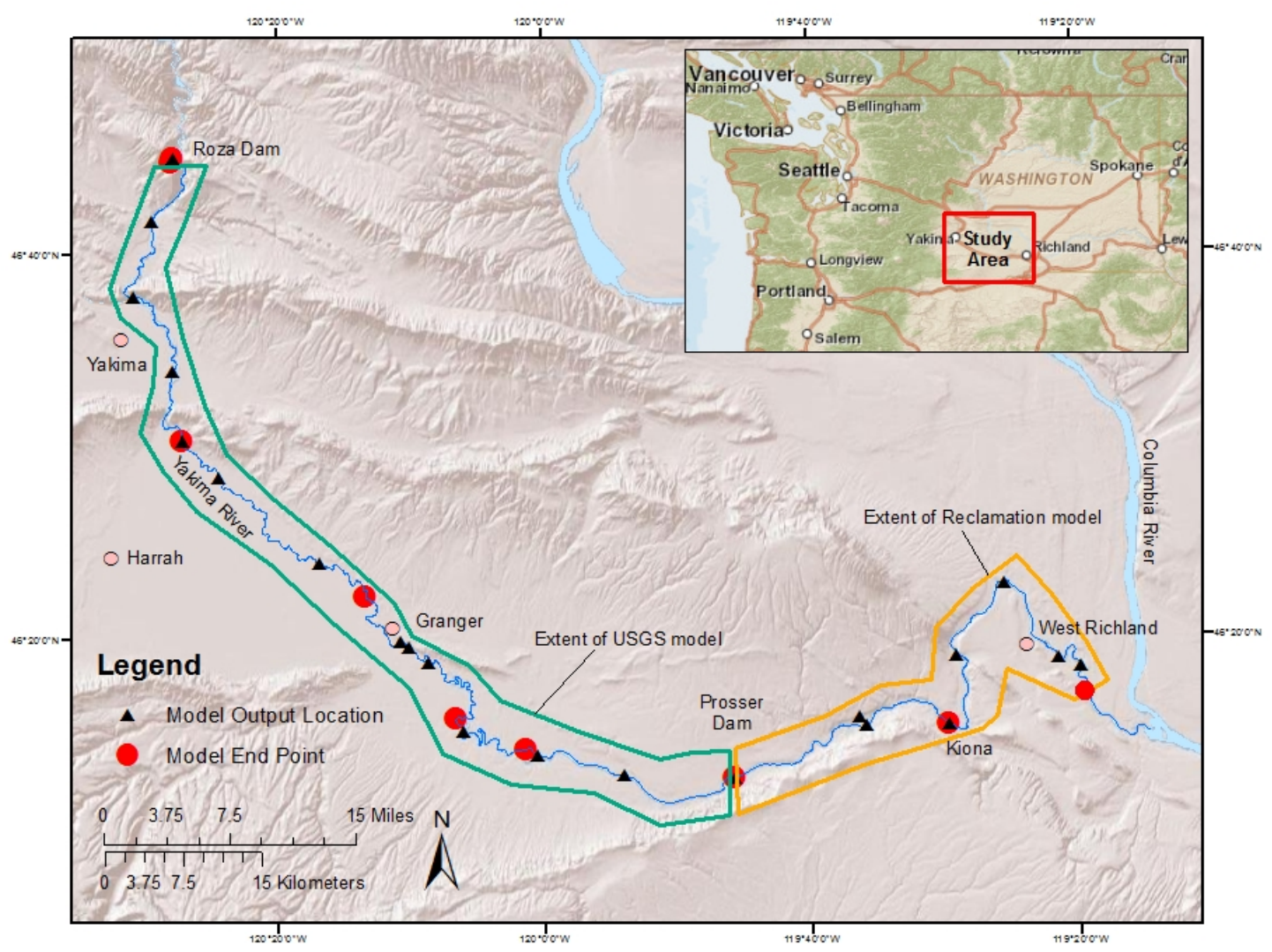

Figure 1. Map showing extent of modeled reach of the lower Yakima River main stem, Washington, with model endpoints and model output locations.

The model structure for the main stem between Roza Dam and Prosser Dam is the same as was documented by Voss and others (2008). Model structure for the main stem between Prosser Dam in West Richland was changed by splitting the original model into two models to generate a daily time step: (1) one model extended from Prosser Dam to Kiona, Washington, and (2) one model extended from Kiona, Washington, to the 224 bridge at West Richland, Washington. A schematic view of the entire model structure is shown in figure 2. Each model segment represents 1 day of travel time during mid-summer low-flow conditions. The column on the left contains all modeled streams and returns flowing into the Yakima River main stem, and the column on the right contains all modeled diversions from the main stem. 


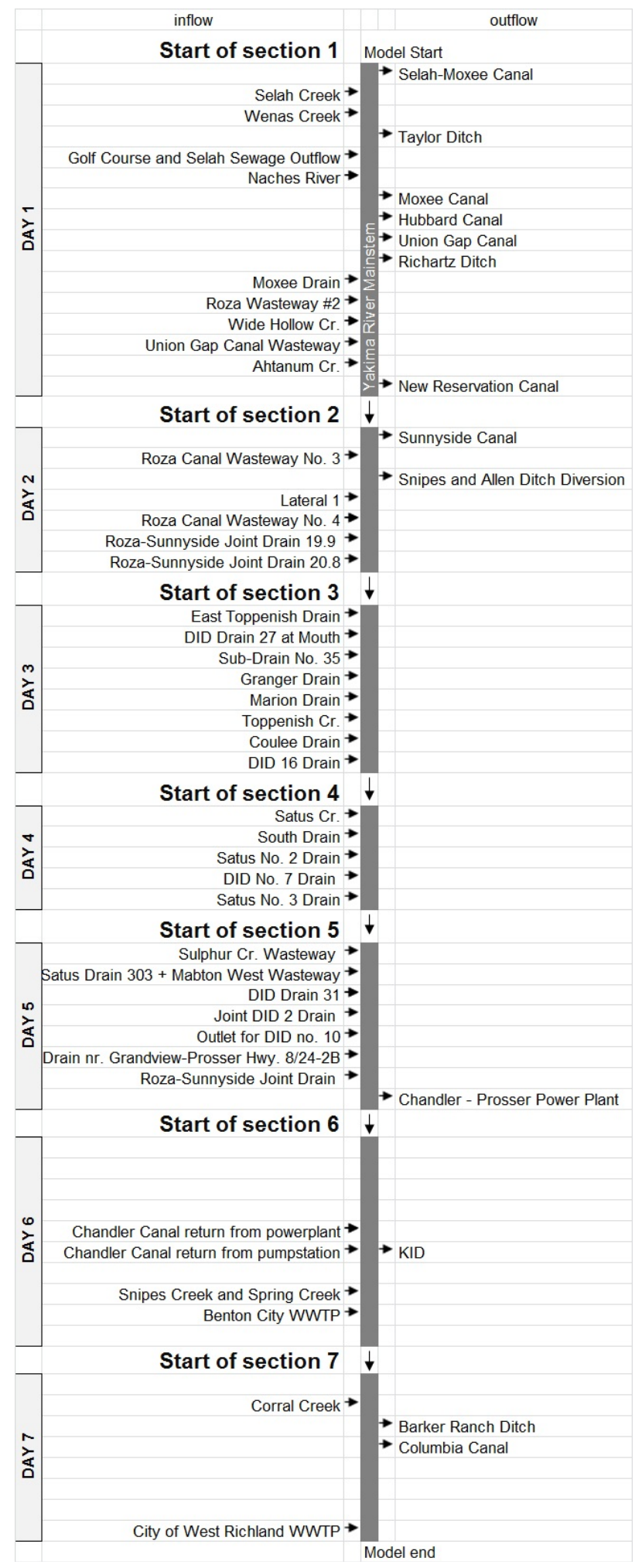

Figure 2. Schematic diagram showing model for the Yakima River main stem with all modeled inflows and outflow for all seven model sections between Roza Dam and West Richland, Washington. 
In addition to data for characterizing stream-channel geometry and shading, SNTEMP requires three sets of input data to run simulations: climate data, flow data, and stream temperatures of all inflowing waterways. Climate data for the first scenario ("Current Conditions" scenario because it simulated conditions unaffected by climate change) used data compiled from two sources: the National Oceanic and Atmospheric Administration's National Weather Service station at the Yakima Air Terminal (National Oceanic and Atmospheric Administration, 2012, station ID = KYKM), and the Washington AgriMet weather station in Harrah, Washington (Agrimet, 2012, station ID = HRHW). Climate data for the second scenario ("Plus 1") were the same as data used for the Current Conditions scenario except that the average daily air temperatures were adjusted $1^{\circ} \mathrm{C}$ higher using a method described in Mastin (2008). Climate data for the third scenario ("Plus 2") also were the same as data used for the Current Conditions scenario, but with the average daily air temperature adjusted $2^{\circ} \mathrm{C}$ higher, again using the method described in Mastin (2008). The increases in air temperature were simulated by applying monthly adjustments (that averaged a 1 or $2^{\circ} \mathrm{C}$ annual increase), as shown in figure 3 .

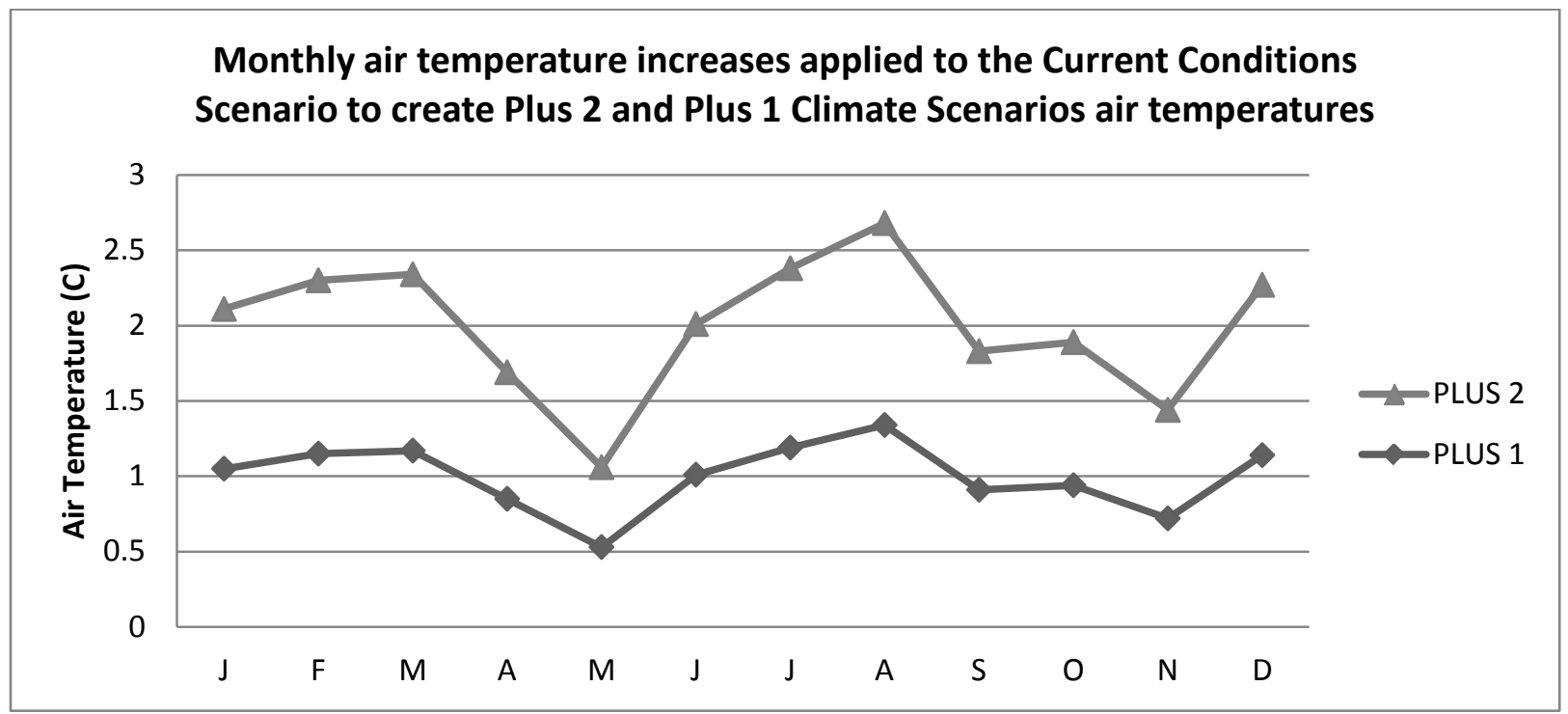

Figure 3. Graph showing monthly air temperature increases applied to the Current Conditions scenario to create the adjusted air temperatures for the Plus 2 and Plus 1 climate scenarios.

SNTEMP does not have hydrologic modeling capabilities; therefore, all flows used in the model must be created from historical flow measurements or flow predicted by hydrologic models. Flow data for the three climate scenarios were generated using a watershed model developed by the USGS, coupled with a river and reservoir-management model developed by Reclamation (Mastin and Sharp, 2006).

The watershed model used is the Precipitation Runoff Modeling System (PRMS) model. PRMS is a deterministic, distributed-parameter, watershed model developed to evaluate the impacts of various combinations of precipitation, temperature, and land use on streamflow and general basin hydrology. Each hydrologic component used to generate streamflow is represented within PRMS by a process algorithm based on a physical law or an empirical relationship with measured or calculated characteristics. Distributed-parameter capabilities of PRMS are provided by partitioning a basin into Hydrologic Response Units (HRUs), using characteristics such as 
slope, aspect, elevation, vegetation type, soil type, and precipitation distribution. These HRUs are assumed to be homogeneous with respect to their hydrologic response. For each HRU, a water balance is computed each day, and an energy balance is computed twice each day. PRMS is conceptualized as a series of reservoirs (impervious zone, soil zone, subsurface, and groundwater) whose outputs by HRU combine to produce the daily basin response.

Output from the PRMS model was used as input to the reservoir-management model developed using RiverWare software. RiverWare is a model-building tool used to develop waterdistribution models for operations and planning. The model for the Yakima River consists of a network of reservoirs, diversions, river reaches, confluences, and other components. Operations policy and rules associated with reservoirs or other system components within the basin are used to control flows throughout the system. Output data from the RiverWare model were used as input to the SNTEMP model for all three climate scenarios.

Initial daily mean water temperatures for all inflowing waterways (fig. 2) in the model were estimated using empirical equations developed for the existing USGS model. The exceptions were initial water temperatures for Satus Creek, which were provided by a model developed by the Columbia River Inter-tribal Fish Commission.

SNTEMP requires nine input files (table 1) to run a simulation for a single reach. The files are fixed-format text files and their file structure is described in the SNTEMP user's manual (Theurer and others, 1984).

Table 1. Typical input files for one Stream Network Temperature Model.

\begin{tabular}{|l|l|}
\hline \multicolumn{1}{|c|}{ File name } & \multicolumn{1}{c|}{ File function } \\
\hline Jobfile.txt & Controls simulation operation \\
\hline Metdat.txt & Contains input climate data for simulation \\
\hline Hyddat.txt & Contains input flow and water temperature data for simulation \\
\hline Timedat.txt & Defines time step for simulation \\
\hline Skelton.txt & Defines stream network structure of model \\
\hline Geom.txt & Defines stream geometry of model \\
\hline Study.txt & Defines locations for generating simulation output \\
\hline Hydnode.txt & Defines hydrology structure of model \\
\hline Shade.txt & Defines amount and type of shading occurring along the river \\
\hline
\end{tabular}

Although SNTEMP can span a multiple-year simulation period when percent cloud cover is used as input to the climate data file (as a surrogate input for solar radiation), SNTEMP only can span a 1-year simulation period when directly measured solar radiation is used as input. This limited capability probably is a result of SNTEMP being developed at a time when long records of daily solar radiation measurements were not available. However, because only direct solar radiation data were available from the weather stations used for this study, the study required that a climate scenario's 25-year simulation period encompass 25 separate simulations with a unique climate input file for each year for each segment of the model. Therefore, generating daily values for seven segment models linked in series required a total of 525 SNTEMP model runs for three climate scenarios with 25-year simulation periods. 


\section{Problems with Running the SNTEMP Model in Series}

Achieving the project objective of generating daily maximum and mean water temperatures for the three climate scenarios required running 525 separate SNTEMP simulations (7 segments $\times 3$ scenarios $\times 25$ years). However, SNTEMP was not designed to be run in series, and the setup of the SNTEMP model runs is manual, time-consuming, and prone to error. Project requirements presented the following challenges:

Challenge 1: Various combinations of the nine input files must be manually swapped in and out of the execution directory for each year and segment.

Running multiple simulations requires that different combinations of input files be swapped in and out of processing directories, and if the correct set of files is not present in the right directory when the model is run, this could result in erroneous output that might not be detected in the analysis phase of the project. Keeping track of the appropriate files to manually swap in and out of the processing directory is a tedious accounting process for 525 model runs and is highly prone to error as a manual process. The following files (in table 2) had to be swapped in and out of the processing directory for each of the 25 years in a simulation period:

Table 2. Stream Network Temperature Model input files that had to be swapped in and out of the processing directory for each of the 25 years in a simulation period.

\begin{tabular}{|l|l|}
\hline \multicolumn{1}{|c|}{ File } & \multicolumn{1}{c|}{ Description } \\
\hline Metdat.txt & Contains input climate data for simulation \\
\hline Hyddat.txt & Contains input flow and water temperature data for simulation \\
\hline Timedat.txt & Varies by whether or not the year is a leap year \\
\hline
\end{tabular}

The following files (in table 3) also had to be swapped in and out of the processing directory for each of the seven segments:

Table 3. Stream Network Temperature Model input files that had to be swapped in and out of the processing directory for each of the seven segments.

\begin{tabular}{|l|l|}
\hline \multicolumn{1}{|c|}{ File } & \\
\hline JobFile.txt & Controls simulation operation \\
\hline Skelton.txt & Defines stream network structure of model \\
\hline Geom.txt & Defines stream geometry of model \\
\hline Study.txt & Defines locations for generating simulation output \\
\hline Hydnode.txt & Defines hydrology structure of model \\
\hline Shade.txt & Defines amount and type of shading occurring along the river \\
\hline
\end{tabular}

Challenge 2: Input data must be manually integrated from various sources into input files with complex logic and structure.

SNTEMP is not designed to interact with a database. All data input to SNTEMP must be managed through text files. As designed, to complete one model run for a single river segment, data must be downloaded from databases, spreadsheets, XML, and flat files and then manually assembled with a text editor in the complex format specified in the SNTEMP user's manual. Input files contain data dependencies in which the value of one parameter determines the existence of other parameters within the same input file or other input files. Learning to construct correctly the 
input file formats is time-consuming, and manual assembly of input files is prone to data entry errors that might be detected by abnormal error termination of the model run. Otherwise, input data errors might not be detected at all, leading to erroneous conclusions.

In addition to integrating input data from various sources, because SNTEMP was not designed to be run in series, the output of one model run would have had to be used as input to the next model run so that output files could be manually deconstructed and reconstituted into complex input file formats. Without a model automation program, this time-consuming and errorprone process would have had to be performed manually 525 times to meet project objectives.

\section{Challenge 3: SNTEMP model does not interact with databases.}

Large amounts of input data cannot easily be associated with output data when these data are stored in files rather than in a relational database that allows queries to be easily constructed for data analysis. Because data are stored in files rather than in a relational database, flexible analysis tools (such as generation of dynamic graphs based on user-selected criterion) cannot be easily developed.

Solution

To overcome these three challenges, we used Microsoft ${ }^{\circledR}$ SQL Server's Integration Services (SSIS) to automate database-driven execution of the model. SSIS was used to develop programs to:

1. Import data from various sources into a unified database,

2. Automate extraction of data from the database to create model input files,

3. Execute the model and control the flow of files in and out of the processing directory,

4. Import model results into a relational database,

5. Create the next input file from the output of the previous run, and

6. Generate dynamic graphs of simulation results based on user-selected criterion .

SSIS consists of tasks (or units of work) and program control flow and data integration tasks that can be arranged on a user-interface and programmed using Dot Net Code, SQL statements, and stored procedures. These graphical units of work can be manually manipulated within the SSIS interface to easily refine and revise process work flows to meet changing project requirements.

\section{Process Flow}

The process flow for model execution was analyzed, as shown in figure 4. The looping starts by selecting data for all the nodes in the first segment for the first year of the simulation period, and writing them to the appropriate SNTEMP input files. The model is then executed and the results are written back to the database. The process is repeated for the remaining segments where the output from an upstream segment is used as input to the next downstream segment. These steps are then repeated for each year of the simulation period for each of the three scenarios.

\section{Design of Database and Model Run Automation Program}

Design objectives for the model automation program included the ability to easily add scenarios, years, segments, and stream nodes to the model without changing underlying code for the automation program. This objective was accomplished by creating a database design that 
would drive execution of the automation program. The database consisted of tables where scenario, years, segments, and stream nodes could be added easily as data, and the program was designed to use this configuration data to control execution of various tasks. Tasks controlled by this data included:

- Swapping files in and out of the processing directory based on year and segment. See Challenge 1 for a description the issues associated with manual file swapping.

- Automation of input files generated from data stored in the database. This eliminated the error-prone and time-consuming processes described in Challenges 2 and 3.

- Import of output data into a relational database. This allowed for easy analysis of the data and for automated construction of input files from output of a previous run. Importing data from the output files into the database allowed input data to be associated easily with output data (see Challenge 3), and analysis tools could be developed to meet various analysis needs. The dynamic graphs (created using SQL Server Reporting Services) included in this report are examples of the types of tools that can be created if data are in a relational database.

Additionally, program automation created a testable and repeatable process that can be used to verify the accuracy of the model and to refine iteratively the input data and processes. Program automation also saved project money because files did not need to be manually assembled nor did complex accounting need to be performed to determine which input files to move into the processing directory. Program automation also improved the accuracy of the model runs.

\section{Generation of Input Data into the Database}

A series of calculations were performed for preparing model input data. Air temperatures for the two climate scenarios were calculated by applying monthly adjustment factors shown in figure 2. Flow data for all the scenarios were imported from the Reclamation RiverWare model and daily flows were calculated for all ungaged inflowing and outflowing streams. Daily initial water temperatures for all inflows to the model were then generated using regression equations that related water temperature to air temperature or to air temperature and flow. The initial water temperatures for Satus Creek from the Columbia River Inter-Tribal Fish Commission (CRITFC) model were added to the database. 


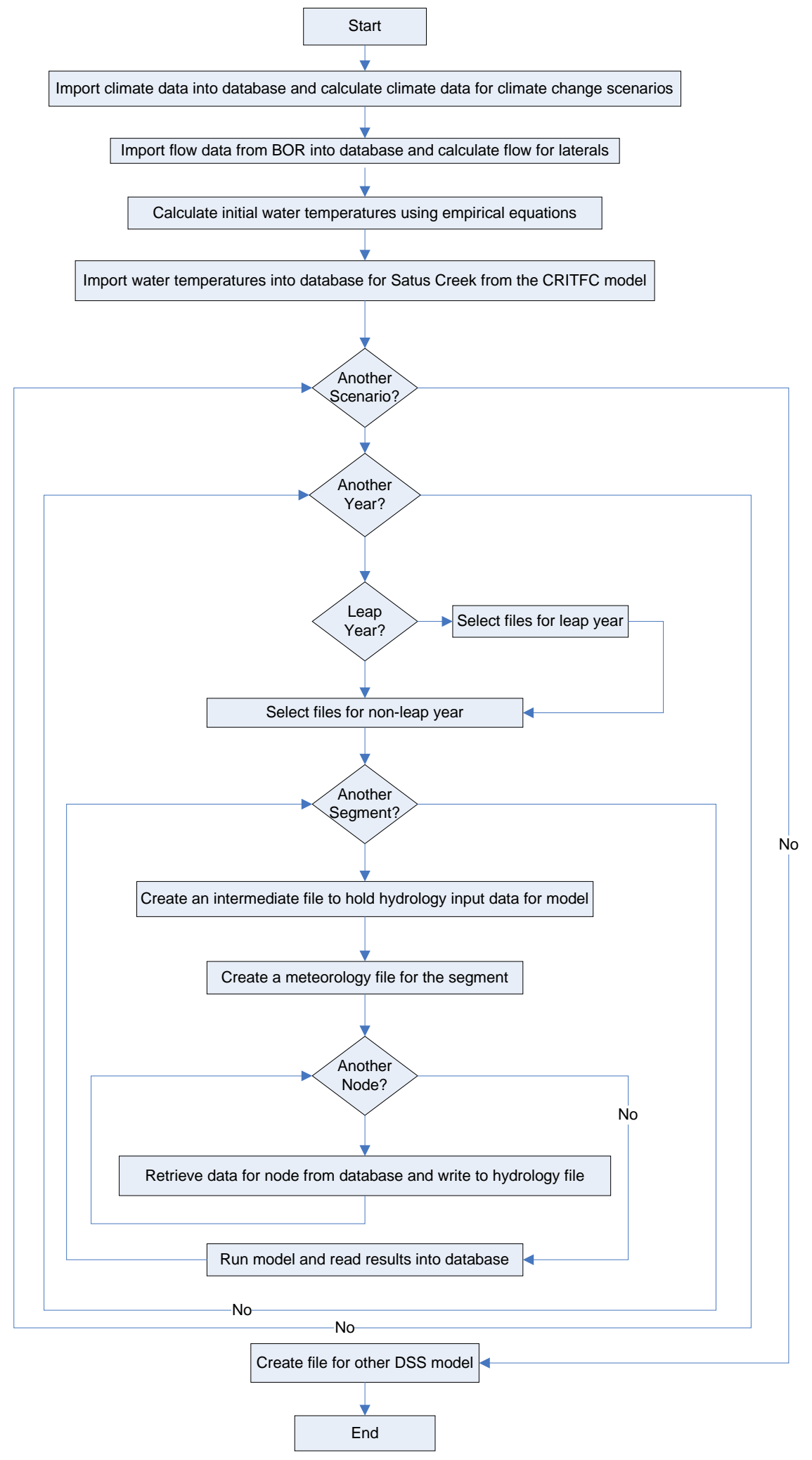

Figure 4. Diagram showing logic flow for Model Automation Program. 


\section{Results}

The two linked models were used without making modifications to their stream geometry data. Both models had been calibrated and validated when they initially were developed but recalibrating and validating the linked models were beyond the scope of this study. Simulation data were compared to data measured at a Reclamation Hydromet gage to obtain a general indication of model performance. Table 4 shows monthly average mean daily measured and simulated water temperatures for 2002-05, measured at the Reclamation Hydromet gage at Kiona, Washington (Bureau of Reclamation, 2012, station ID = KIOW).

Table 4. Average daily mean water temperature for Kiona, Washington 2002-05.

\begin{tabular}{|c|c|c|c|c|}
\hline Month & $\begin{array}{c}\text { Average measured mean } \\
\text { daily water temperature } \\
\text { (degrees Celsius) }\end{array}$ & $\begin{array}{c}\text { Average simulated } \\
\text { mean daily water } \\
\text { temperature (degrees } \\
\text { Celsius) } \\
\text { Current Conditions } \\
\text { scenario }\end{array}$ & $\begin{array}{c}\text { Average simulated } \\
\text { mean daily water } \\
\text { temperature (degrees } \\
\text { Celsius) } \\
\text { Plus 1 scenario }\end{array}$ & $\begin{array}{c}\text { Average simulated } \\
\text { mean daily water } \\
\text { temperature (degrees } \\
\text { Celsius) } \\
\text { Plus 2 scenario }\end{array}$ \\
\hline JAN & 4.3 & 5.2 & 5.4 & 5.5 \\
\hline FEB & 5.4 & 7.3 & 7.5 & 7.8 \\
\hline MAR & 9.3 & 11.1 & 11.2 & 11.4 \\
\hline APR & 13.9 & 14.4 & 14.7 & 19.1 \\
\hline MAY & 17.3 & 18.4 & 18.8 & 22.6 \\
\hline JUNE & 20.2 & 21.8 & 22.3 & 25.3 \\
\hline JULY & 24.4 & 25.0 & 25.2 & 23.9 \\
\hline AUG & 23.2 & 23.5 & 23.7 & 19.5 \\
\hline SEPT & 19.1 & 18.9 & 19.1 & 7.4 \\
\hline OCT & 13.3 & 12.9 & 13.1 & 7.2 \\
\hline NOV & 7.1 & 6.9 & 7.0 & 5.6 \\
\hline DEC & 4.6 & 4.9 & 5.3 & \\
\hline
\end{tabular}

The difference between average monthly mean daily water temperatures predicted for the Current Conditions scenario and measured values at the Kiona gage was between $1.9^{\circ}$ and $1.1^{\mathrm{O}} \mathrm{C}$ for February, March, May, and June, and less than $0.8^{\circ} \mathrm{C}$ for the remaining months of the year. The difference between current conditions and measured monthly values for the two warmest months (July and August) were $0.5^{\circ} \mathrm{C}$ and $0.2^{\circ} \mathrm{C}$, respectively. 
Programs were developed for creating interactive graphs for visualizing simulation results using SQL Server Reporting Services (SSRS). SSRS was used to create a graphing tool that would allow users to select various criteria (distance, scenario, months, etc.) to meet their analysis needs. SSRS is a server-based report generating software that is integrated with the SQL Server 2008 R2 database. The user can graph the differences in mean monthly water temperature between the Current Conditions and either the Plus 1 or Plus 2 scenarios at selected distances along the main stem for selected months. Water temperature differences between the Plus 1 and Current Conditions scenarios for the entire modeled main stem for May, June, and July are shown in figure 5. Water temperature differences between the Plus 1 and Current Conditions scenarios for the entire modeled main stem for August, September, and October are shown in figure 6.

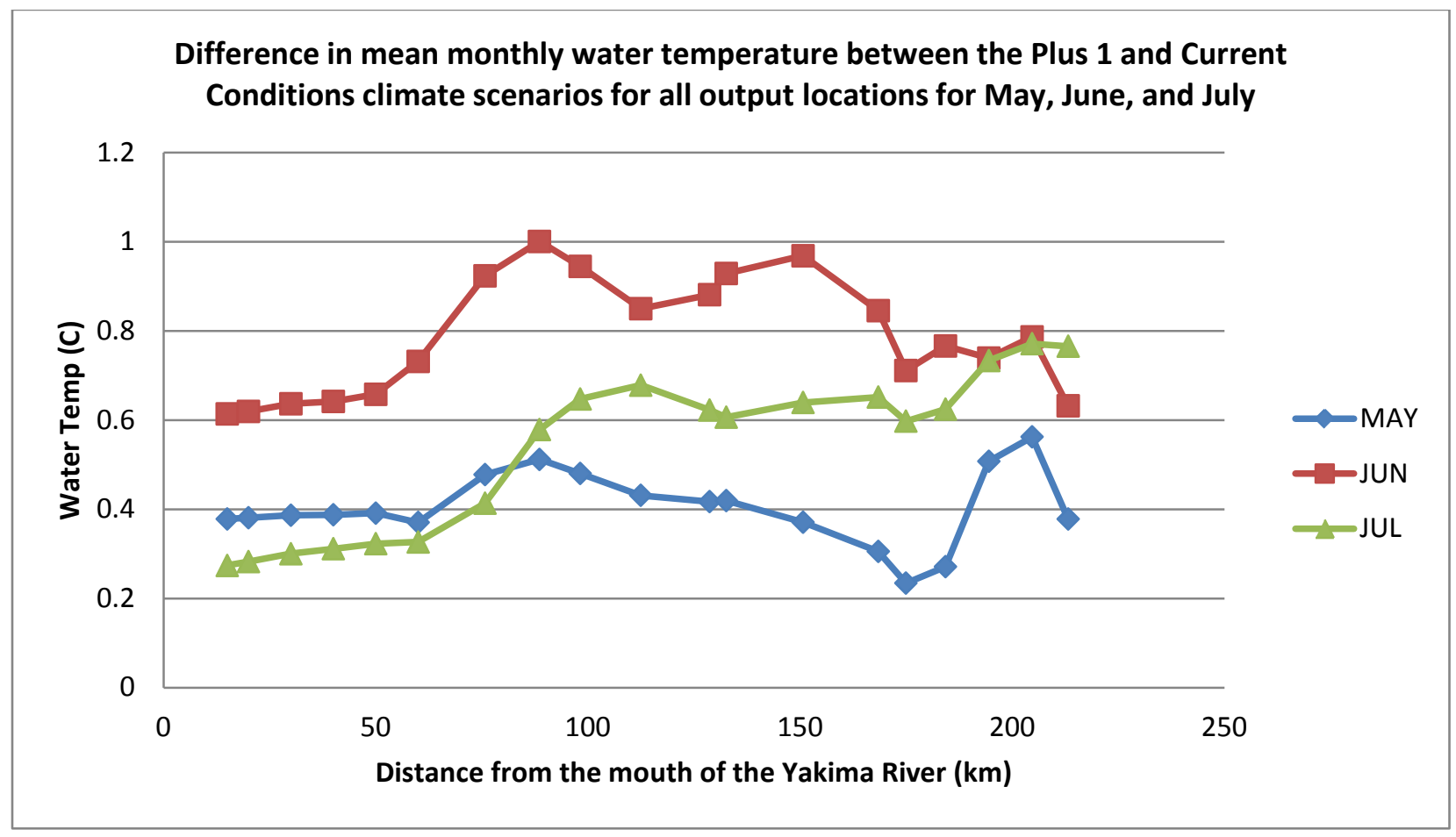

Figure 5. Graph, created with first graphing tool, showing difference in mean monthly water temperature between the Plus 1 and Current Conditions scenarios for all output locations on the modeled Yakima River main stem, Washington, May, June, and July. 


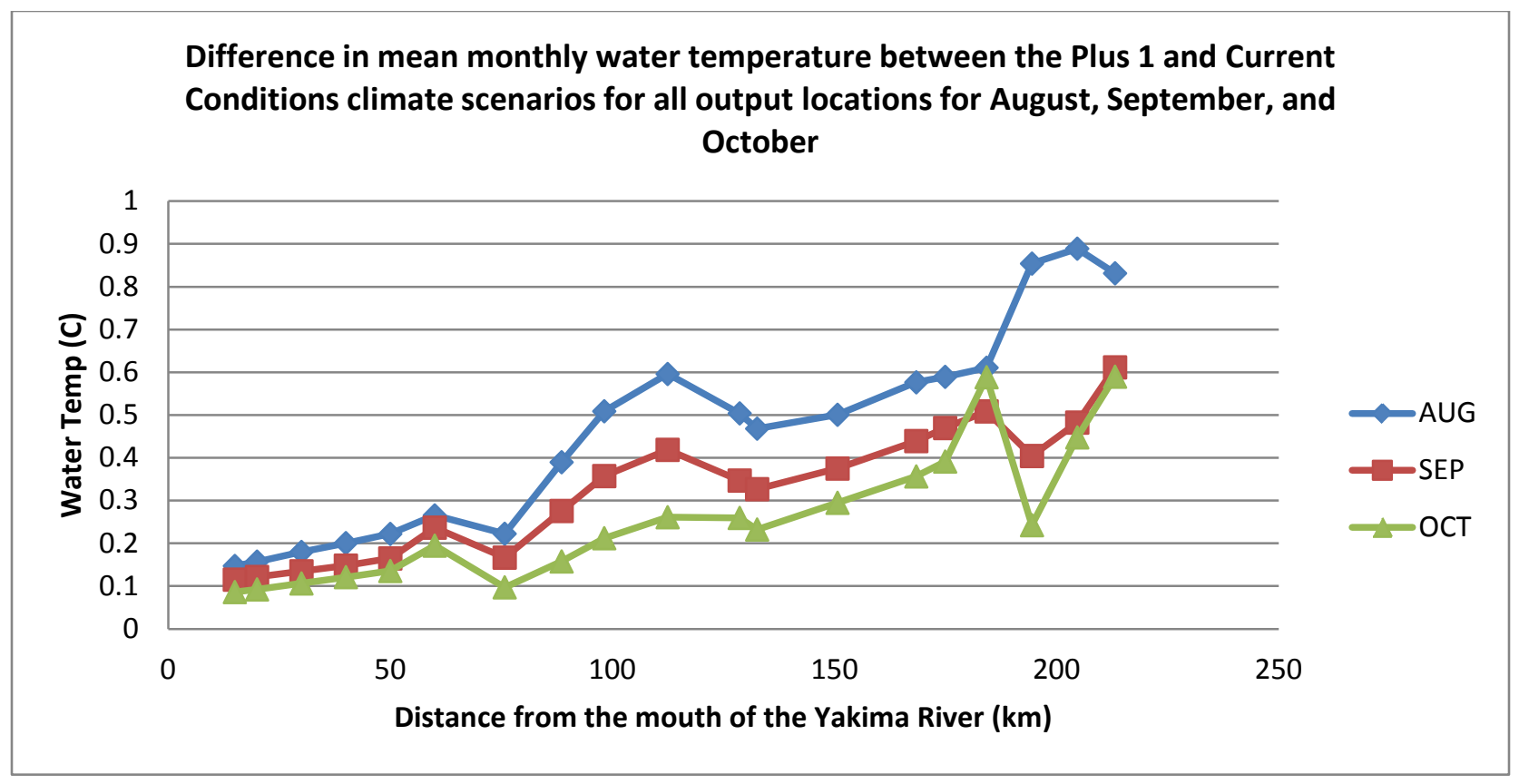

Figure 6. Graph, created with first graphing tool, showing difference in mean monthly water temperature between the Plus 1 and Current Conditions scenarios for all output locations on the modeled Yakima River main stem, Washington, August, September, and October.

A second graphing tool was developed to allow users to graph the differences in mean monthly water temperature between the Current Conditions and either the Plus 1 or Plus 2 scenarios for all months in a year for any combination of output sites. Water temperature differences between the Plus 1 and Current Conditions scenarios for all months of the year for the output sites at distances of 194.47, 184.25, 168.42, 88.57, and $50 \mathrm{~km}$ upstream of the mouth of the river is shown in figure 7 . Water temperature generally becomes less sensitive to air temperature with decreasing distance from the mouth of the river (fig. 7). 


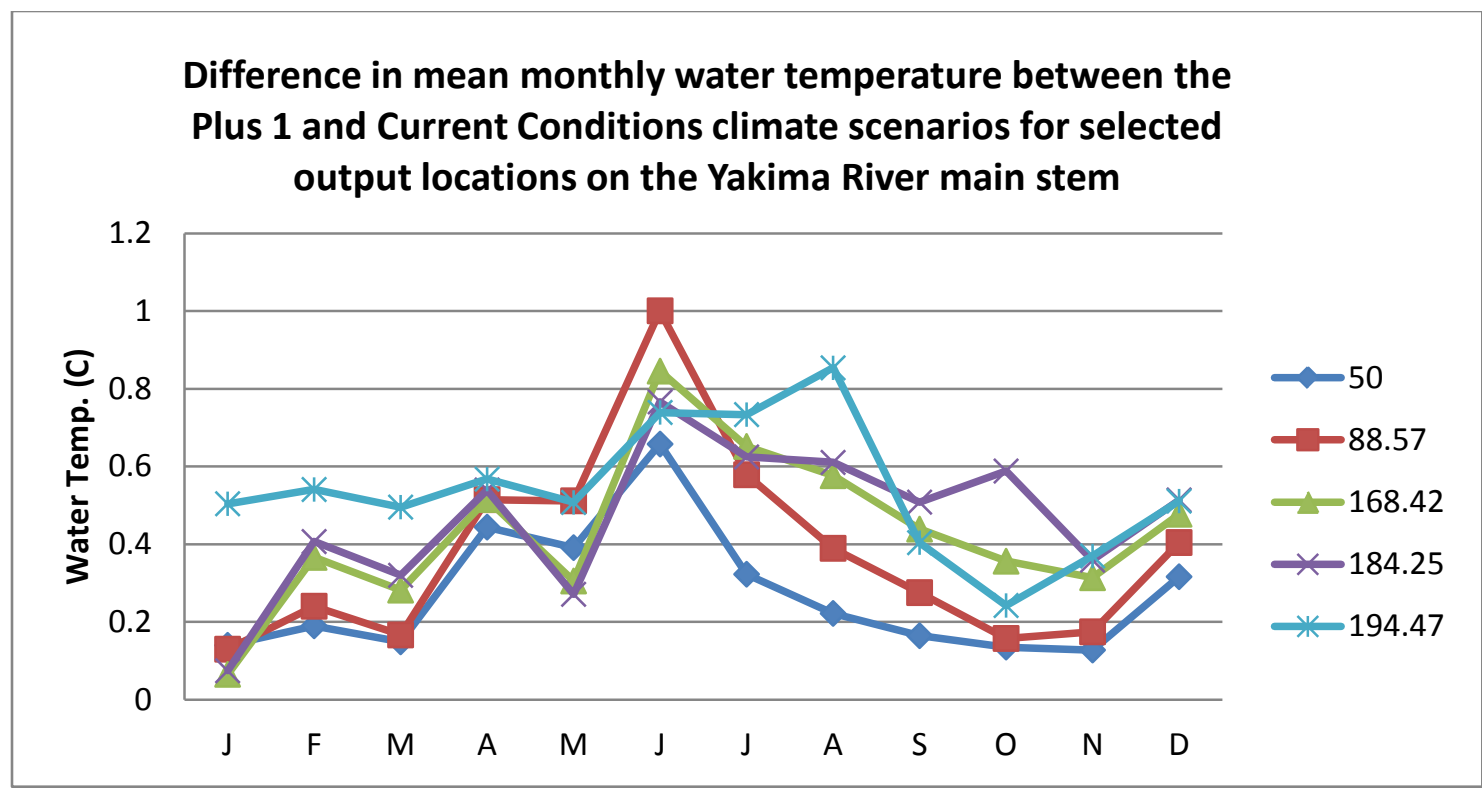

Figure 7. Graph, created with second graphing tool, showing difference in mean monthly water temperature between the Plus 1 and the Current Conditions climate scenarios for selected output locations on the modeled Yakima River main stem, Washington.

A third graphing tool was developed to allow users to graph the differences in daily water temperatures between the Current Conditions and the Plus 1 or Plus 2 scenarios at selected output sites. Figures 8, 9, 10, 11, and 12 are screenshots showing the differences in mean daily water temperatures between the Plus 1 and Plus 2 scenarios and the Current Conditions scenario for sites at distances of 194.47, 184.25, 168.42, 88.57, and $50 \mathrm{~km}$ upstream of the mouth of the river, respectively, for July 1-August 31, 1993 compared to 1993 current conditions.

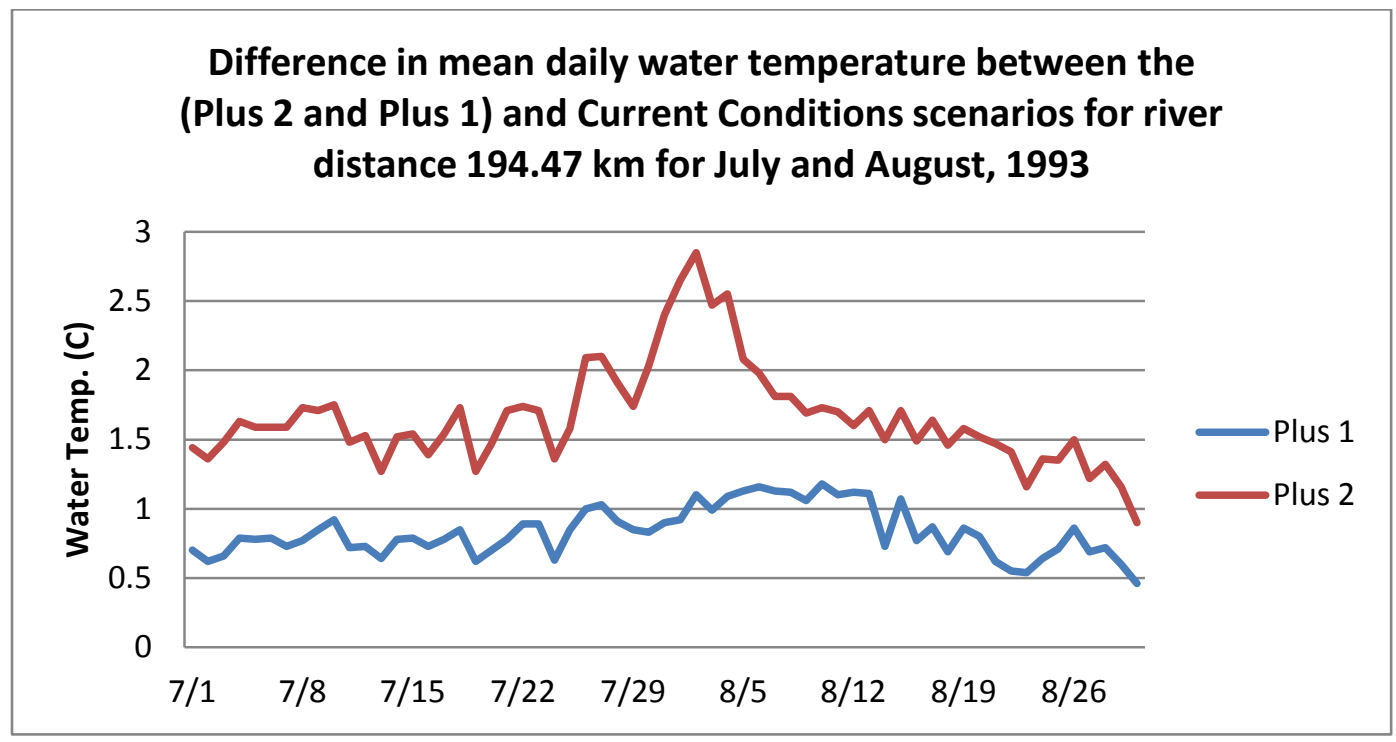

Figure 8. Graph, created with third graphing tool, showing difference in simulated mean daily water temperature between Plus 1 and Plus 2 scenarios and the Current Conditions scenario for the site at a distance of 194.47 kilometers upstream of the mouth of the Yakima River, Washington. 


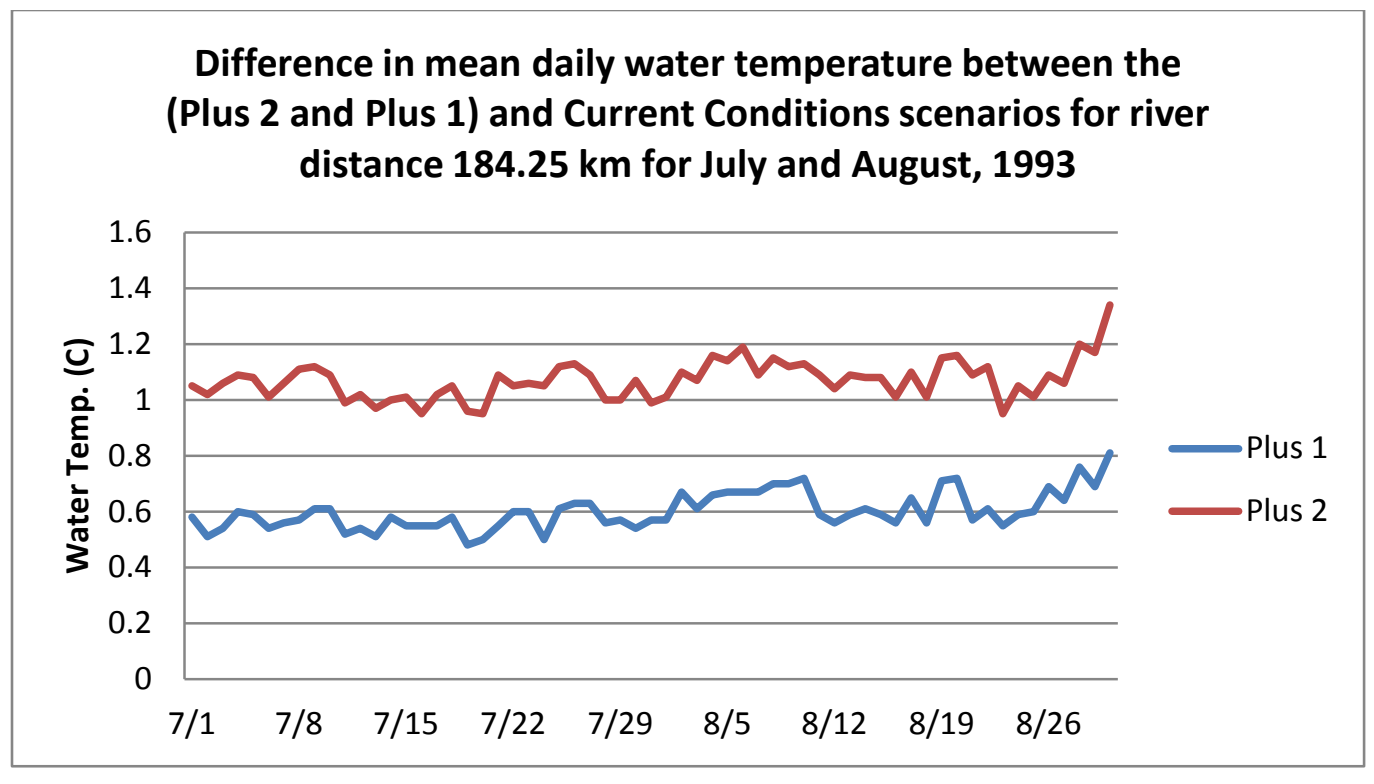

Figure 9. Graph, created with third graphing tool, showing difference in simulated mean daily water temperature between Plus 1 and Plus 2 scenarios and Current Conditions scenario for the site at a distance of 184.25 kilometers upstream of the mouth of the Yakima River, Washington.

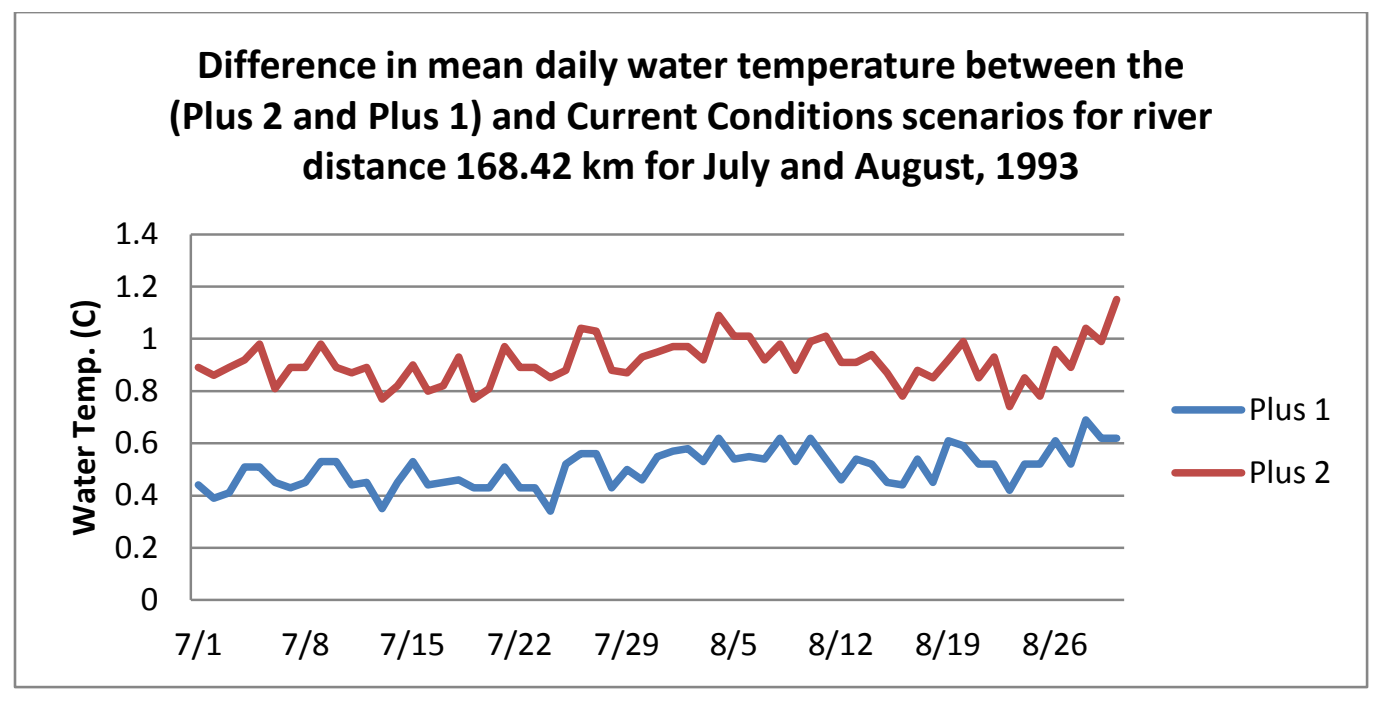

Figure 10. Graph, created with third graphing tool, showing difference in simulated mean daily water temperature between Plus 1 and Plus 2 scenarios and Current Conditions scenario for the site at a distance of 168.42 kilometers upstream of the mouth of the Yakima River, Washington. 


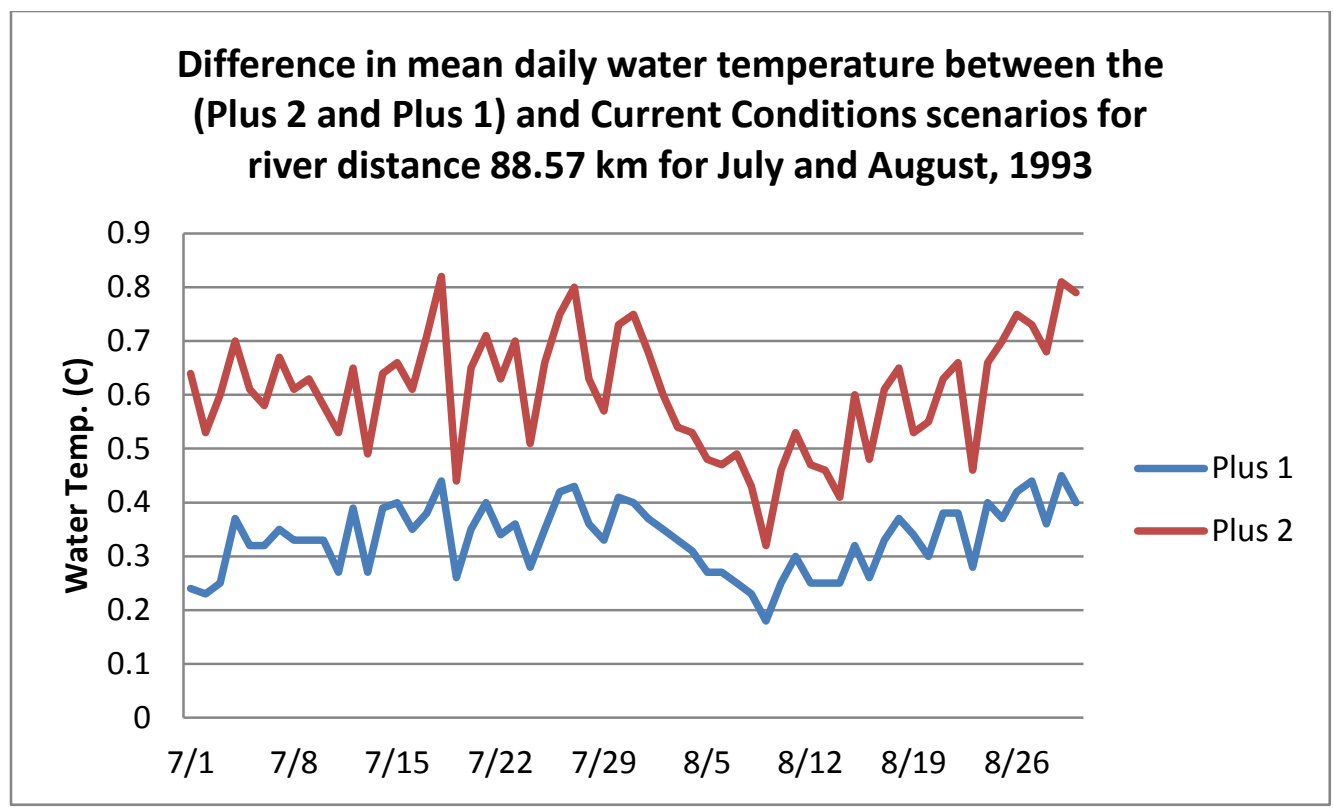

Figure 11. Graph, created with third graphing tool, showing difference in simulated mean daily water temperature between Plus 1 and Plus 2 scenarios and Current Conditions scenario for the site at a distance of 88.57 kilometers upstream of the mouth of the Yakima River, Washington.

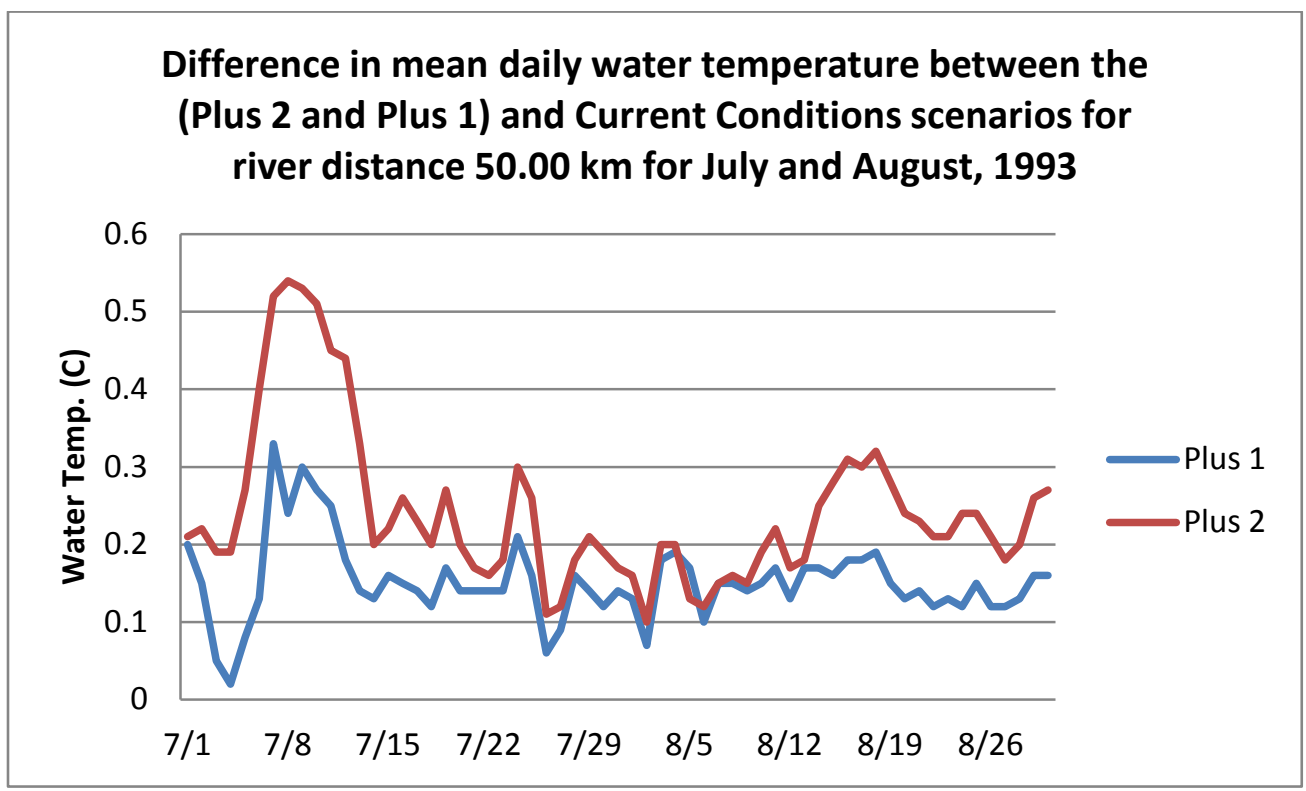

Figure 12. Graph, created with third graphing tool, showing difference in simulated mean daily water temperature between Plus 1 and Plus 2 scenarios and Current Conditions scenario for the site at a distance of 50 kilometers upstream of the mouth of the Yakima River, Washington. 
The daily graph tool provides users with a more detailed view of water temperature response to air temperature at the output sites. The series of graphs show that water temperature becomes less sensitive to air temperature with decreasing kilometer distance from the mouth of the river.

\section{Discussion}

This paper describes a cost-effective approach for running multiple simulations. The database-driven design made the model flexible and extendable to different scenarios, node permutations, new weather information, and hydrology attributes. Database-driven design also eliminated the need to manually assemble files, to manually set up parameters, and to perform other labor-intensive processes. Once the system was in place, the simulations for the three climate scenarios ran efficiently and successfully without the need of other user interventions.

The single relational database developed for the project proved effective for storing and managing all project data. Input data from many sources and in many formats were imported into the database. The entire database easily can be backed up and sent to other researchers for their analysis. Integrated database tools are available for performing complex queries and for performing data mining to detect and characterize patterns in the input data and simulation results for potential future projects. Database tools also are available for providing reports, charts, and data on the Internet if there is an interest.

The SSIS packages accessed model configuration data (such as scenarios, years, segments, and stream nodes) from a relational database and produced model input files for 525 simulations without introducing errors into the model runs. The packages were designed so that a new user also can run simulations without having to learn the SNTEMP file formats. Because the system is database-driven, users can add data for numerous scenarios to the database, and the SSIS package will automatically adapt to the new changes so that no SNTEMP file manipulation is necessary. Because all input and output data are in a relational database, cross comparisons between different scenarios are relatively easy to make by querying the database.

A comparison of Current Conditions scenario results with measured data at the Hydromet gage located at Kiona, Washington, showed that the model had the best agreement with measured values from mid-summer through late autumn. This result was expected because both of the linked models initially were developed to simulate conditions for the growing season when air temperatures are warm and the main stem flows are relatively low and stable. The more divergence from growing season conditions, the more error is introduced into the model and the more care should be taken in interpreting the simulation results.

For this study, the model was used to explore the relative sensitivity of water temperatures to changes in air temperature between locations along the Yakima River main stem. However, the model also could be used to test water temperature sensitivity to other variables, such as changes in flow or shading. 
The method described in this report can be applied to creatively combine a wide range of models, regardless of the coding language in which they are written. These models can easily be integrated into a decision-support system or loosely linked to a set of models for analysis. Possible opportunities for future work could include the following:

- Link a Geographic Information System (GIS) to the system. A GIS could be programmed so that a user could set the locations on the main stem of a river where output was desired on a map, and the GIS would calculate characteristics of the site (such as river mile or elevation) and write the data to an SNTEMP stream geometry input file. A GIS also could be linked so that it could automatically display simulation results using timeaware animation to illustrate seasonal water temperature patterns.

- Develop a user interface. Many types of interfaces could be developed to help users interact with SNTEMP. For example, options could be added to allow a user to increase or decrease daily flows for all the segments in a linked series of segment models by a percentage during a simulation period to perform sensitivity analysis of water temperatures to flow.

- Add analysis tools. By storing all model input and output data in a relational database, a user can take advantage of the analytic and reporting tools within the database. For example, SQL Server 2008 R2 has a suite of algorithms and tools for performing data mining to explore patterns in data. Tools also exist to generate many types of charts that can give the user an intuitive understanding of the distributions of data for variables of interest.

- Develop a Web interface. SQL Server 2008 R2 also has tools for linking the relational database to the Internet. Projects can be developed for allowing the public to explore recently run simulation results by creating and downloading interactive reports and charts and to download input data and simulation results in a wide variety of file formats, such as Microsoft $^{\circledR}$ Excel, XML, pdf, and delimited text files.

- SSIS also can be used to link any model to other models. Output from one model can be used as input to another model, and loops also can be created so models feed back to each other. 


\section{Summary}

Selecting the methodology for linking and operating models is an important consideration when designing a decision-support system. This often overlooked topic can have a substantial impact on the cost of setting up and operating a decision-support system. It also can affect the system's capacity to integrate models with complex input or output file formats, thereby limiting the creative combinations of models that can be used.

The information in this report outlines a database-driven approach for automating laborintensive models for multiple simulations. Two existing water temperature models were linked in series to simulate daily maximum and mean water temperature at user-specified locations on the Yakima River main stem between Roza Dam and the 224 bridge at West Richland, Washington. Data flows for automating simulations were defined and diagrammed. A relational database was designed, and data from numerous sources and formats were imported to its tables. SQL Server 2008 R2 Integration Services was used to develop packages to create SNTEMP input files, to run SNTEMP, and to process simulation output over multiple simulation runs.

SNTEMP was successfully linked to the relational database. The database-driven approach used made it possible for different management and climate scenarios to be run without the user having to perform any file manipulation. All data management for the model was handled using database management tools.

Water temperatures were simulated for a "Current Conditions" scenario (1980-2005) and for "Plus 1" and "Plus 2" climate warming scenarios where the average annual air temperatures used in the Current Conditions scenario were increased by 1 degree Celsius $\left({ }^{\circ} \mathrm{C}\right)$ and $2^{\circ} \mathrm{C}$, respectively. Monthly mean daily water temperatures (2002-05) predicted for the Current Conditions scenario were compared to measured values at the Hydromet gage at Kiona, Washington. Differences were between $1.9^{\circ}$ and $1.1^{\circ} \mathrm{C}$ for February, March, May, and June, but less than $0.8^{\circ} \mathrm{C}$ for the remaining months of the year. The difference between simulated current conditions and measured monthly values for the two warmest months were small $\left(0.5^{\circ} \mathrm{C}\right.$ for July and $0.2^{\circ} \mathrm{C}$ for August).

Interactive graphing tools were developed for exploring the relative sensitivity of average monthly and mean daily water temperature to increases in air temperatures. The model predicted that water temperature generally becomes less sensitive to air temperature increases the farther the location is downstream of Roza Dam, and that the difference between climate warming scenarios also decreases with downstream distance from the dam. The model predicted that the largest changes in sensitivity occur from August to October.

Much work has been done to create useful models for many disciplines ranging from hydrology to sociology to economics. Using a data-driven approach with a relational database technology makes it possible to develop creative and flexible decision-support systems for investigating management options for complex systems. 


\section{Acknowledgments}

The authors would like to acknowledge Mark Mastin and Cindi Barton of the USGS

Washington Water Science Center in Tacoma, Washington, for their support for this project.

\section{References Cited}

Agrimet, 2012, The Pacific Northwest Cooperative Agricultural Weather Network, Harrah, Washington AgriMet Station (HRHW), accessed on December 5, 2012, http://www.usbr.gov/pn/agrimet/agrimetmap/hrhwda.html

Bartholow, J.M., 2000, The stream segment and stream network temperature models-A selfstudy course: U.S. Geological Survey Open-File Report 99-112, 276 p. (Also available at http://pubs.er.usgs.gov/publication/ofr99112.)

Bureau of Reclamation, 2012, Yakima Hydromet Real-Time (DAYFILES) Data Access, accessed 12/5/2012, http://www.usbr.gov/pn/hydromet/yakima/yakwebdayread.html

Mastin, M.C., 2008, Effects of potential future warming on runoff in the Yakima River Basin, Washington, U.S. Geological Survey Scientific Investigations Report 2008-5124, 12 p. (Also available at $h t t p: / / p u b s . e r . u s g s . g o v / p u b l i c a t i o n / s i r 20085124$.

Mastin, Mark, and Sharp, Warren, 2006, Comparison of simulated runoff in the Yakima River Basin, Washington, for present and global climate-change conditions: Presentation by U.S. Geological Survey at the Climate Impacts Group, Climate and Water Resource Forecasts for the 2007 Water Year Conference, Kelso, Washington, October 3, 2006, 25 p.

National Oceanic and Atmospheric Administration, 2012, Climate Data Online, accessed 12/5/2012, http://www.ncdc.noaa.gov/cdo-web/

Payne, T.R., Bremm, D.J., and Monk, P.A. 2001, Evaluating the Columbia River Pump Exchange Project using the Stream Network Temperature [SNTEMP] model: Report prepared by Thomas R. Payne and Associates, Arcata, Calif., for Kennewick Irrigation District, Kennewick, Wash.

U.S. Geological Survey, 2012, Stream Network and Stream Segment Temperature Models Software: U,S, Geological Survey Fort Collins Science Center web site, accessed October 24, 2012, at http://www.fort.usgs.gov/products/software/SNTEMP/.

Theurer, F.D., Voos, K.A., and Miller, W.J., 1984, Instream water-temperature model-Instream flow information Paper 16: U.S. Fish and Wildlife Service, FWS/OBS-84/15, 335 p.

Voss, F.D., Curran, C.A., and Mastin, M.C., 2008, Modeling water temperature in the Yakima River, Washington, from Roza Diversion Dam to Prosser Dam, 2005-06: U.S. Geological Survey Scientific Investigations Report 2008-5070, 43 p. (Also available at http://pubs.er.usgs.gov/publication/sir20085070.) 
Publishing support provided by the U.S. Geological Survey

Publishing Network, Tacoma Publishing Service Center

For more information concerning the research in this report, contact the

Director, Washington Water Science Center

U.S. Geological Survey

934 Broadway, Suite 300

Tacoma, Washington 98402

http://wa.water.usgs.gov 


\section{总}

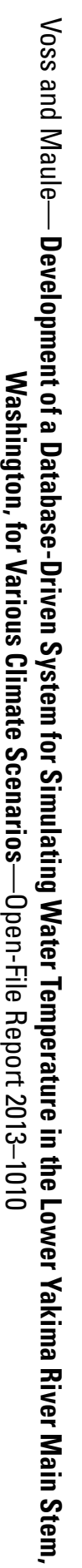

9 Printed on recycled paper 